\title{
Effect of Socio-Demographic Variables on Social and Emotional Maturity of Tribal Adolescents
}

\author{
K. Samhitha ${ }^{1}$, P. Sreedevi ${ }^{1}$, M. Sarada Devi ${ }^{1}$ and R. Neela Rani ${ }^{2}$ \\ ${ }^{1}$ Department of Human Development and Family Studies, ${ }^{2}$ Department of Extension \\ Education and Communication Management, Hyderabad, Professor Jayashankar Telangana \\ State Agricultural University, Telangana, India \\ *Corresponding author
}

\section{A B S T R A C T}

\section{Keywords}

Social maturity, Emotional maturity, Tribal adolescents, Adilabad district, Yashwir Singh and Mahesh Bhargava, Tribes

\section{Article Info}

\section{Accepted:}

28 April 2020

Available Online:

10 May 2020

\begin{abstract}
This research studied the relationship between socio-demographic variables with respect to social and emotional maturity of tribal adolescents in Adilabad district of Telangana state. A self-designed interview schedule was used to study the sociodemographic characteristics of the respondents. Social maturity of the respondents was assessed by using Rao's Social Maturity Scale and Emotional Maturity was assessed using scale developed by Yashwir Singh and Mahesh Bhargava. The data was analysed using Pearson correlation coefficient. The interview schedule was administered on 120adolescents out of which 60 are boys and 60 are girls who were selected using purposive random sampling method. Ex-post factor research design was used for the study. The results revealed that, age of the adolescent and mother's occupation are positively correlated with social maturity. With respect to emotional maturity, age of the adolescent is positively correlated whereas Birth order and mother's occupation are negatively correlated.
\end{abstract}

\section{Introduction}

Adolescence is crucial and significant period in an individual's life in which the individual becomes integrated into the society of the adults. During this phase, they acquire the abilities to deal with abstractions and possibilities. Adolescents develop socially and emotionally during this time. It is a period of heightened emotionality. Social development is one of the major developmental areas in which an individual pass through. An individual is expected to exhibit socially matured behaviours and relationships with age-mates irrespective of their sex and achieve socially responsible behaviours by developing intellectual skills and the concepts essential for civic competency.

Social maturity is the level of social skills and social awareness that an individual has achieved related to particular norms of that age group (Raj, 1996). Research studies also 
revealed that the tribal students were backward in social activities and participation as compared to their counterparts i.e., nontribal students due to far from the mainstream of the society (Pradhan, 2010 and Dubey, 2010). Most of the tribal adolescents were suffering from various psychosocial problems like inferiority complex especially girls (Das et al., 2016).

Emotional maturity is a process in which the personality is continually striving for greater sense of emotional health, both intrapsychically and intra personally (Smitson, 1974). Studies on emotional maturity of adolescents revealed that majority of the adolescents were extremely emotionally immature. Adolescents from rural areas had extremely unstable emotional maturity (Yolila and Talawar, 2013). Tribal adolescents were suffering with emotional and behavioural problems like anxiety, depression, frustrations, mental upsets, attention problems and exhibited rule-breaking behaviour (Gopal and Ashok, 2012), they were emotionally immature when compared to non-tribal adolescents (Deva, 2015).

The main objectives include to study the relationship between socio-demographic variables and social maturity among tribal adolescents. And also to study the relationship between socio-demographic variables and emotional maturity among tribal adolescents.

\section{Materials and Methods}

Interview schedule was prepared which includes general profile of the respondents. It also covers the details of Adolescent related like Age, Gender, Birth Order, Educational Qualification, Type of school. Family related: Type of family. Parent related: Parent's education (Father's and Mother's) and parent's occupation (Father's and Mother's).

Rao's social maturity scale developed by Dr.
Nalini Rao was used to find out the social maturity of the respondents. The scale has three major components and 90 items under nine dimensions-Personal Adequacy: Work Orientation, Self-Direction, Ability to take Stress, Interpersonal Adequacy: Communication, Enlightened Trust, Cooperation and Social Adequacy: Social Commitment, Social Tolerance and Openness to change.

Emotional Maturity Scale developed by Yashwir Singh and Mahesh Bhargava was used to find out the emotional maturity levels of the respondents. Emotional Maturity Scale is a self-reporting five-point scale in which 48 items under five broad categories i.e., Emotional stability, Emotional progression, Social adjustment, Personality integration and Independence.

Statistical analysis was done by using Pearson correlation coefficient.

\section{Results and Discussion}

The relationship between socio-demographic variables with social maturity and emotional maturity of tribal adolescents can be understood by looking at the below tables. 1 and 1.2 respectively. Pearson correlation coefficient was used for statistical analysis.

The table. 1 depicts that, age was found to be positively and significantly related with social maturity of tribal adolescents. It means higher the age of the adolescent, better will be the social maturity. This might be due to the reason that, as age advances, ability to make interpersonal relations, behaviour appropriateness, social adjustments, problem solving and judgment capabilities, understanding social rules and role expectations increases. In contrary Anitha and Jebaseelan (2017) found that age had no significant relation with social maturity scores. 
Positive and significant relationship was observed between Mother's occupation and social maturity. It means that, higher the mother's involvement in professional works (teaching, project supervision, data operators, record assistants and nursing), better the social maturity in terms of proper orientation towards work of the adolescent, more directed towards life, possess good communication skills, commitment towards progress of society and ability to form interpersonal interactions. This might be due to the reason that, children of working mothers are more exposed to quality social settings and interactions which helps them to understand and develop decent behaviours towards others. Similar results were found in a study conducted by Pant and Singh (2017); Rani and Prabha (2007) in which adolescents of working mothers were found significantly more socially matured than those of nonworking mothers.

The variables like gender, birth order, class of study, type of school, type of family, parent's education and father's occupation of trial adolescents did not show any significant relationship with Social maturity.

The table. 2 depicts a positive and significant relation between age and emotional maturity. It indicates that, higher the age, better the emotional maturity. This might be due to the reason that as age increases, the capacity to dispose off problems, handling irritabilities, aggressiveness, inferiorities decrease and social adaptability, rationalised thinking, optimism and independent behaviours in daily life activities increases.

Birth order had found to be significantly and negatively related with emotional maturity. It means that, later borns had low emotional maturity when compared to first borns. Later borns had lower capacities to handle vulnerabilities, temper tantrums, restlessness, irrational in thinking and were emotionally dependent. This might be due to the reason that, first-born children are exposed to more maternal and paternal participation as there were no other children to divide the attention thus, they tend to spend more time with adults and grows up faster and become more emotionally mature. Similar results were found in a study conducted by Pant and Singh (2017) who found that, first borns are more emotionally stable than later borns.

Significant negative relation was found between mother's occupation and emotional maturity. It indicates that, higher the mothers involved in professional skilled jobs (teaching, clerical, typing and nursing), lesser will be the emotional stability, progressive behaviours, personality integration and emotional independence. The reason could be that, employed mothers are more subjected to role conflicts as they have to perform dual roles i.e., domestic duties as well as occupational duties because of which they get a very less time to interact and spend with the adolescent. Because of the stress and strain at home and uncongenial atmosphere, the adolescents develop emotional instabilities, irritabilities and were unable to manage as well as control emotions. Similar results were found in a study by Pant and Singh (2017) in which, adolescents of non-working mothers were found to have significantly better emotional maturity than adolescents of working mothers. Whereas Hangal et al., (2007) found that, children of employed mothers had high emotional maturity than the children of unemployed mothers. In another study by Saimons (2014) found no significance difference between the effects of maternal employment on emotional maturity. The variables like gender, class of study, type of school, type of family, parental education and father's occupation did not show any significant relationship with emotional maturity. 
Table.1 Correlation between socio-demographic variables and social maturity

\begin{tabular}{|c|l|c|}
\hline S. No & Variable & Social Maturity \\
\hline $\mathbf{1 .}$ & Age & $.190^{*}$ \\
\hline $\mathbf{2 .}$ & Gender & .138 \\
\hline $\mathbf{3 .}$ & Birth Order & .160 \\
\hline $\mathbf{4 .}$ & Class of Study & .021 \\
\hline $\mathbf{5 .}$ & Type of School/College & .021 \\
\hline $\mathbf{6 .}$ & Type of Family & .024 \\
\hline $\mathbf{7 .}$ & Father's Education & .031 \\
\hline $\mathbf{8 .}$ & Mother's Education & .024 \\
\hline $\mathbf{9 .}$ & Father's Occupation & .068 \\
\hline $\mathbf{1 0 .}$ & Mother's Occupation & $.347^{* *}$ \\
\hline
\end{tabular}

Table.1 Correlation between socio-demographic variables and emotional maturity

\begin{tabular}{|c|l|c|}
\hline S. No & Variable & Emotional Maturity \\
\hline $\mathbf{1 .}$ & Age & $.476^{*}$ \\
\hline $\mathbf{2 .}$ & Gender & .109 \\
\hline $\mathbf{3 .}$ & Birth Order & $-.426^{*}$ \\
\hline $\mathbf{4 .}$ & Class of Study & .105 \\
\hline $\mathbf{5 .}$ & Type of School/College & .101 \\
\hline $\mathbf{6 .}$ & Type of Family & -.039 \\
\hline $\mathbf{7 .}$ & Father's Education & .122 \\
\hline $\mathbf{8 .}$ & Mother's Education & .121 \\
\hline $\mathbf{9 .}$ & Father's Occupation & .142 \\
\hline $\mathbf{1 0 .}$ & Mother's Occupation & $-.534^{* *}$ \\
\hline
\end{tabular}

Conclusion of the study are as follows:

Thus, from the research it can be inferred that, Age is significantly and positively related to both social and emotional maturity of the tribal adolescents. It means that, higher the age better will be the social and emotional maturity (or as age increases, social maturity increases). Mother's occupation is positively related to social maturity whereas it is negatively related to emotional maturity. It means that, higher the mother's occupation better will be the social maturity but lesser will be the emotional maturity of the tribal adolescents.

Social and emotional maturity in an individual is very important for a smooth functioning of their social as well as emotional life in the society. Thus, the factors affecting the social and emotional maturity can be found out through the research and they can be strengthened through organising seminars, workshops, counselling sessions to parents, teachers and all individuals influencing the adolescents.

\section{References}

Anitha, P and Jebaseelan, S. U. 2017. A study on social maturity of the adolescent college students in colleges at Tiruchirappalli. Research on Humanities 
and Social Sciences. 7(17). www.iiste.org.

Das, S., Sanjukta, M., Ashwini, K. M and Soumya, S. S. 2016. Assessment of adolescent problems in tribal adolescent girls: A cross sectional study. International Journal of Community Medicine and Public Health. 3(5):10141019

Deva Anjali, 2015. Emotional Maturity of Tribal and Non-Tribal Pre - Adolescents: A study of Gandhari Region in Nizamabad District. The International Journal of Indian Psychology. 2(4).

Dubey. 2010. Social problems of tribal adolescents. International Journal of Home Science. 3(2): 278-283.

Hangal, S and Aminabhavi, V. A. 2007. Selfconcept, emotional maturity and achievement motivation of the adolescent children of employed mothers and homemakers. Journal of the Indian Academy of Applied Psychology. 33(1): 103110.

Pant, K and Singh, R. 2016. A study on understanding social and emotional maturity of adolescents: analysing impact of birth order. International Academy of Science Engineering and Technology. 5(6): 221-230

Pant, K and Singh, R. 2017. Differences in social and emotional maturity of adolescents across occupational status of mothers. Journal of Psychology. 6(2): 134-141.

Pradhan, K. C. 2010. Getting the Secluded into social-mainstream through micro projects. Dalits and Tribes of India (131-150). New Delhi: Mittal Publication.

Raj, M. 1996. Encyclopaedia Dictionary of psychology and Education, New Delhi: Anmol Publications.

Rani, S, G. and Prabha, R, C. 2008. Social maturity levels of adolescents belonging to different parenting styles. Psycholingua. Agra: Psycho linguistics association of India. 38(2): 185-188.

Rao, N. (2002). Manual for Rao's social maturity scale. National Psychological Corporation, Agra.

Saimons, S. 2014. To study the effect of maternal employment on emotional maturity of adolescents. Journal of International Academic Research for Multi-disciplinary. 1: 23-28.

Singh, Y. and Bhargava, M. 1990. Emotional Maturity Scale. National Psychological Corporation, Agra.

Smitson, W.S. (1974). The meaning of emotional maturity. MH, Winter 58, 911.Singh, 1999.

Venu Gopal, V. D and Ashok, A. 2012. Impact of grade and gender differences on adjustment: A cross sectional study. Social Science International. 29(2): 163177.

Yolila, S. T and Talawar, S. M. 2013. A study of academic achievement, study involvement and emotional maturity of secondary school tribal students of Nagaland. Ph.D dissertation. Bangalore University, India.

\section{How to cite this article:}

Samhitha, K., P. Sreedevi, M. Sarada Devi and Neela Rani, R. 2020. Effect of Socio-Demographic Variables on Social and Emotional Maturity of Tribal Adolescents. Int.J.Curr.Microbiol.App.Sci. 9(05): 3385-3389. doi: https://doi.org/10.20546/ijcmas.2020.905.402 